Artigo original

Hegemonia - Revista Eletrônica de Relações Internacionais do Centro Universitário Unieuro

ISSN: $1809-1261$

UNIEURO, Brasília, número Especial, 2016, pp. 28-45.

Recebido em: 22/7/2016

Avaliado em: 11/8/2016

Aprovado em: 9/9/2016

\title{
Educação nas Prisões: Direito Constitucional
}

\author{
Iolanda Bezerra dos Santos Brandão, ${ }^{1}$ e Lia Scholze ${ }^{2}$
}

Resumo: Este trabalho propõe a reflexão sobre as Políticas Educacionais na modalidade de Educação de Jovens e Adultos em situação de privação de liberdade nos estabelecimentos penais. $O$ processo de democratização da aprendizagem e a universalização dos direitos educacionais receberam ancoragem na Constituição Cidadã de 1988 , atendendo a vontade política da sociedade civil dando espaço e voz para que diferentes segmentos pudessem participar efetivamente da definição e implementação das políticas e práticas educacionais, através da distribuição mais equitativa dos recursos e ampliação da oferta de vagas em todas as modalidades de ensino com a inclusão dos indivíduos em privação de liberdade. Analisa, também a evolução dessas políticas a luz da Lei de Diretrizes e Bases - LDB, PNE, chegando as Diretrizes Educacionais para Oferta de EJA em Privação de Liberdade. A base teórica encontra sustentação em autores como Briceño; Gomes; Neves; Pucci; Sacavino, entre outros, além dos dados do Ministério da Justiça - INFOPEN, IBGE, MEC/FNDE, MEC/INEP, IPEA, Pastoral Carcerária e Organismos Nacionais e Internacionais dos Direitos Humanos.

\footnotetext{
${ }_{1}^{1}$ Professora Doutora em Psicologia Social (PUC/SP). Pesquisadora e Professora do Centro Universitário UNIEURO e Instituto Laboro.

2Professora Doutora em Educação (UFRGS). Pesquisadora e Consultora de Organismos Internacionais.
} 
Artigo original

Hegemonia - Revista Eletrônica de Relações Internacionais do Centro Universitário Unieuro

ISSN: $1809-1261$

UNIEURO, Brasília, número Especial, 2016, pp. 28-45.

Palavras-chave: Educação Prisional; Direitos Humanos; Constituição Cidadã.

Abstract: This paper proposes a reflection over the educational policies on the mode of Educação de Jovens e Adultos (EJA - Young and Adults Education) on deprivation of freedom situation on prisons facilities. The process of democratization of learning and the universalization of educational rights receive basement on Brazilian Constitution of 1988, serving political civil society will and give space and voice to different segments could effectively participate in the definition and implementation of educational policies and practices through the more equitable distribution of resources and increasing the supply of places in all types of education with the inclusion of individuals in prison settings. Analyses too, the evolution of those policies under the Lei de Diretrizes e Bases (LDB - Law of Guidelines and Basis), Plano Nacional de Educação (PNE - National Plain of Education), approaching the Education Guidelines to EJA offer in deprivation of freedom. The theoretical basis is offer by authors as Briceño; Gomes; Neves; Pucci; Sacavino, among others, besides of Secretary of Justice and others Brazilian's Government offices data - INFOPEN, IBGE, MEC/FNDE, MEC/INEP, IPEA, Prison Ministry and National and International Human Rights Organizations.

Key-words: Education Prison; Human rights; Citizen Constitution (1988).

\section{Introdução}

A situação da educação do Brasil tem avançado muito nos últimos anos a partir da Constituição Cidadã. Foi a Constituição de 1988 que mais contundentemente balanceou o ritmo entre poder e democracia duradoura. Apesar da continuidade do desequilíbrio, favorável aos 
Artigo original

Hegemonia - Revista Eletrônica de Relações Internacionais do Centro Universitário Unieuro

ISSN: $1809-1261$

UNIEURO, Brasília, número Especial, 2016, pp. 28-45.

detentores do poder econômico, e por isso político, entra para o cenário histórico como a Constituição considerada até hoje uma das mais avançadas e democráticas em nível mundial, no que diz respeito aos direitos e garantias individuais do cidadão.

A universalização da educação básica e a eliminação do analfabetismo só serão realidade quando a população composta pelos indivíduos em privação de liberdade, até então descuidada for incluída, e que também Ihes seja garantido o pleno acesso às condições necessárias de estudo.

É preocupante a situação educacional no Sistema Penitenciário Brasileiro contabilizando-se que a população carcerária atinge hoje em torno de 600.000 mil detentos, sendo que destes $73,83 \%$ são jovens entre 18 a 34 anos. A realidade educacional deste universo de pessoas é de $5 \%$ analfabetos e $68 \%$ sem educação fundamental completa. Se tratada a questão da infra-estrutura, sabe-se da precariedade da escola pública que por ser em sua grande maioria reservada para os pobres não recebe dos municípios e estados os cuidados necessários. Em se tratando do Sistema Prisional, as condições são mais precárias ou inexistentes. Outros fatores que dificultam a oferta deste serviço são a preparação dos professores, a tensão natural neste tipo de ambiente, a dificuldade de entendimento entre os agentes de segurança e os professores, os materiais e conteúdos inadequados, falta de locais de estudo, bibliotecas e laboratórios.

A partir das Diretrizes Nacionais para Oferta de Educação para Jovens e Adultos em Situação de Privação de Liberdade nos Estabelecimentos Penais, cujo parecer foi homologado por despacho do Ministro da Educação e publicado DOU em 07 de Maio de 2010 
Artigo original

Hegemonia - Revista Eletrônica de Relações Internacionais do Centro Universitário Unieuro

ISSN: $1809-1261$

UNIEURO, Brasília, número Especial, 2016, pp. 28-45.

esperava-se que essa situação fosse revertida, ou no mínimo amenizada.

2. O desafio da garantia do direito à educação no Sistema Prisional

Considerando o ser humano na sua disposição ontológica de superação contínua, diferentemente, dos outros seres vivos, que procura sobrepujar sua condição de existência do mundo, sendo a educação ferramenta fundamental para a realização dessa vocação humana. Vocação que, para se realizar plenamente, necessita sempre da participação do outro nesse acreditar na superação e no processo de reeducação.

No Brasil, as condições educacionais, principalmente, nas escolas públicas, apesar dos diversos Programas existentes, ainda deixa muito a desejar. Ao analisar o desempenho dos estudantes nas diferentes avaliações propostas pelo Estado, percebe-se que a dívida da sociedade ainda é muito grande, pois a qualidade do ensino oferecido não permite que muitos concretizem o sonho de concluir os estudos e finalmente frequentar os bancos do ensino superior.

O rápido crescimento das matrículas, neste nível educacional, deu margem à criação de instituições com precárias condições de funcionamento tanto em relação à qualidade do ensino ministrado quanto à sua infra-estrutura.

Esta expansão necessita de acompanhamento permanente com ações avaliativas visando garantir a qualidade do ensino oferecido. São grandes e recorrentes os desafios da democratização do acesso, considerada a diferenciação da oferta de modo a garantir o 
Artigo original

Hegemonia - Revista Eletrônica de Relações Internacionais do Centro Universitário Unieuro

ISSN: $1809-1261$

UNIEURO, Brasília, número Especial, 2016, pp. 28-45.

atendimento das demandas da economia e da sociedade, a excelência da formação oferecida e uma equação adequada de financiamento da expansão (NEVES, 2012).

Nos presídios, as condições de estudos são ainda mais precárias. O êxito nos estudos depende de uma série de fatores, dentre eles, a necessidade de quebrar a barreira da dicotomia educação x segurança que cria sérios impeditivos ao correto desempenho e desenvolvimento de ações didático-pedagógicas, que sejam metodologicamente eficazes para o bom desenvolvimento das práticas educativas ali propostas. Medidas como convênios com entidades públicas ou particulares, que instalem escolas ou ofereçam cursos especializados podem representar solução para as condições locais de atendimento como por exemplo, instalação de uma biblioteca, para uso de todas as categorias de reclusos, provida de livros instrutivos, recreativos e didáticos (BRASIL, 1995).

Pensar educação no espaço prisional depende de se compreender o estado de tensão contínua que envolve todos os atores que ali transitam diariamente sejam os próprios presos, como também o quadro de profissionais encarregados das mais diversas funções. Dentre esses funcionários estão de um lado os agentes operadores da execução penal, no caso os agentes penitenciários e do outro os professores que muitas vezes convivem de forma conflituosa, considerando os diferentes papéis que executam. "Os agentes penitenciários, geralmente, encaram os docentes como profissionais que atuam de forma muito emotiva com os apenados, não levando em consideração o grau de periculosidade dos mesmos" (Diretrizes Nacionais para EJA, 2010 p.21). 
Artigo original

Hegemonia - Revista Eletrônica de Relações Internacionais do Centro Universitário Unieuro

ISSN: $1809-1261$

UNIEURO, Brasília, número Especial, 2016, pp. 28-45.

Desta maneira, os trabalhos desenvolvidos no espaço escolar dos presídios são desqualificados e constantemente ameaçados, haja vista sua dependência rotineira de consentimentos e autorização da gestão da unidade penal. "[...] o excesso de zelo pela segurança geralmente impede qualquer criatividade docente: passar filmes, convidar palestrantes, desenvolver pesquisas, atividades coletivas, em muitos estabelecimentos penais são atividades quase impossíveis." (Diretrizes Nacionais para EJA, 2010, p.21).

São poucos os Estados que realizam uma ambientação dos funcionários da área educacional para atuarem no sistema penitenciário. Na sua grande maioria, os profissionais que atuam nessas escolas possuem contratos temporários, resultando na rotatividade constante e na falta de uma proposta político-pedagógica consolidada. No caso dos docentes, muitos deles não possuem experiência de EJA. Poucas são as escolas que tem Projeto PolíticoPedagógico ou que estão inseridas dentro de uma Proposta PolíticoInstitucional de execução penal da unidade.

As atuais Diretrizes Curriculares Nacionais para os Cursos de Licenciatura não estimulam as Instituições de Ensino Superior - IES que têm Cursos voltados à formação de professores a investirem em uma matriz curricular que possibilite ao discente visualizar alternativas profissionais na área de educação além dos postos cotidianamente apresentados no mercado de trabalho. Com raras exceções, o que se vê é a propagação de Currículos e Programas destinados à presença docente nas tradicionais áreas conhecidas no desempenho de sua atividade profissional. 
Artigo original

Hegemonia - Revista Eletrônica de Relações Internacionais do Centro Universitário Unieuro

ISSN: $1809-1261$

UNIEURO, Brasília, número Especial, 2016, pp. 28-45.

Tais carências comprovam a necessidade imediata de reformulação dos currículos dos cursos de pedagogia e demais licenciaturas, introduzindo temas das ciências sociais e políticas sociais bem como da pedagogia social em que as universidades incentivem e invistam em projetos de extensão e pesquisas que possibilitem a maior compreensão desses espaços, inacreditavelmente, ainda tão invisíveis na nossa sociedade (Diretrizes Nacionais, 2010, p.21).

Outro fator, presente nas políticas educacionais do Sistema Penitenciário é a carência de materiais voltados às necessidades educacionais da EJA, a realidade é que muitas das bibliotecas nesses espaços, quando existentes, possuem acervo desatualizado (livros infantis e didáticos com conteúdo e metodologia inadequados). Quanto à infra-estrutura, são geralmente espaços improvisados e precários sem qualquer organização ao fim a que se destinam.

Com relação às ações educacionais, essas são realizadas indiscriminadamente sem levar em consideração as características do público alvo do regime de atendimento da unidade (provisório, fechado, semi-aberto e aberto), bem como das características físicas de cada unidade (Diretrizes Nacionais, 2010, p.21).

Ainda que a centralidade desse trabalho seja discutir as Políticas Educacionais para o atendimento dos apenados na proposta educacional da EJA, cabe ressaltar que outro universo de apenados que já possui ensino médio, pode freqüentar, desde que passe pelo processo seletivo da IES, como estudantes, os espaços educacionais do ensino superior. Porém, hoje, as IES ainda não prepararam seus quadros de professores, funcionários e nem seus currículos e 
Artigo original

Hegemonia - Revista Eletrônica de Relações Internacionais do Centro Universitário Unieuro

ISSN: $1809-1261$

UNIEURO, Brasília, número Especial, 2016, pp. 28-45.

programas para receber o aluno oriundo do Sistema Prisional ou egresso dele.

\section{Educação como básico social}

O fenômeno crescente de aumento da criminalidade e da violência deve ser observado a partir da análise de alguns fatores que podem ser considerados como os principais agentes desencadeadores desse fenômeno. Nessa perspectiva, a falta de uma política efetiva de distribuição de renda; a falta de acesso das classes de baixa renda aos sistemas educacionais; a valorização da violência, através da exposição pública nos meios de entretenimento que apresentam a violência física e psíquica como valores a ser nutridos, a competição excessiva como proposta de respostas às demandas sociais e a desesperança em encontrar caminhos saudáveis que propulsionem bases de planejamento de sua existência.

Neste sentido, a educação como instrumento de ressocialização dos indivíduos deve ser um dos principais objetivos traçados pelo Sistema Prisional, mas as condições oferecidas nem de longe viabilizam a possibilidade de ela ser efetivada. Ofertar um nível de educação adequado aos apenados, contemplando valores da cultura educacional formal, que fortaleça respostas positivas frente às demandas sociais, encontrando espaços para realização pessoal e profissional, se constituiriam em instrumentos positivos de reinserção dessas pessoas na vida social.

Pelo acesso à alfabetização e uma educação com valores que favoreçam o convívio na sociedade, que possibilite o surgimento de 
Artigo original

Hegemonia - Revista Eletrônica de Relações Internacionais do Centro Universitário Unieuro

ISSN: $1809-1261$

UNIEURO, Brasília, número Especial, 2016, pp. 28-45.

vivências positivas e expectativas futuras promissoras, para que a vida passe a ter passado (ressignificado), presente e futuro. A Educação é uma porta segura para mediar a relação do apenado com a sociedade. Oferecer educação é oferecer esperança no processo de construção do conhecimento que forja o cidadão, e na outra via, desconstrói o criminoso.

$\mathrm{Na}$ perspectiva de Sacavino (2007) A democratização da aprendizagem e a universalização dos direitos educacionais requerem tanto vontade política quanto uma sociedade civil fortalecida, com espaço e voz para poder participar efetivamente do sistema educacional. Nesse sentido, é necessário repensar a definição e a implementação das políticas e práticas educacionais. A distribuição dos recursos deve ser mais equitativa para que o direito à educação, garantido pela Constituição Federal, seja efetivado.

Analisando os dados sobre a escolaridade da população prisional brasileira, é possível identificar que em todos os anos da série histórica 2005-2012 (BRASIL, 2014, p. 22) a maior parte dos (as) presos (as) não chegou a completar o ensino fundamental. Para esse mesmo período constata-se que uma parte muito restrita da população prisional possuía ensino superior ainda que nos últimos anos vem crescendo a parcela da população prisional que atingiu o ensino médio. Ainda para essa mesma série histórica, constata-se uma tímida queda no percentual de analfabetos que passa de 5,8 em 2005 para 5,4\% em 2012 (INFOPEN).

A partir dos dados foi possível aferir (por ausência de informações sobre escolaridade) que a maioria da população prisional era composta por jovens entre 18 e 34 anos. Em 2005 dentre os presos sobre os 
Artigo original

Hegemonia - Revista Eletrônica de Relações Internacionais do Centro Universitário Unieuro

ISSN: $1809-1261$

UNIEURO, Brasília, número Especial, 2016, pp. 28-45.

quais havia essa informação disponível, 53.599 tinham entre 18 e 24 anos e 42.689, entre 25 e 29 anos, já em 2012, 143.501 tinham de 18 a 24 anos e 266.356 destes tinham entre 25 e 29 anos. Segundo o Estatuto da Juventude, 54,8\% da população encarcerada no Brasil era formada por jovens (Lei no 12.852/213), ou seja, tinha menos de 29 anos.

Pensar o projeto de desenvolvimento do país requer pensar o projeto de desenvolvimento de sua juventude. Dados como os apresentados acima demonstram quais são as prioridades que estão sendo enfatizado pelos governantes, o custo Brasil é um custo presente e uma conta a ser paga no futuro. Inda mais, considerando o crescente envelhecimento da população brasileira. O país não pode prescindir da participação da sua juventude no desenvolvimento da nação. ${ }^{3}$

Ao comparar o custo aluno com o custo preso, percebe-se que existe um dispêndio de recursos no Sistema Prisional muito maior que no Sistema Educacional. Enquanto o custo aluno no Brasil é de 2.576,36 (Portaria n.317, de 27 de março 2015 (MEC; FNDE), na Educação Fundamental, o Brasil gasta 1,7 mil x mês x preso (mais de 40 mil $x$ ano $x$ preso em presídio federal).

No Ensino Médio, o gasto é de 2,3 mil x aluno de acordo com entrevista de Daniel Cara, coordenador da Campanha Nacional pelo

\footnotetext{
${ }^{3}$ Calcula-se que o custo médio mensal de um apenado no Brasil, computando nesse cálculo despesas com alimentação, salários de funcionários, material de limpeza e higiene, água, luz, gás, telefone, combustível, medicamentos, manutenção predial e de equipamentos e manutenção de viaturas seja de $R \$ 750,00$ (setecentos e cinquenta reais) em alguns estados alcançando em outros $R \$ 1.200,00$ (hum mil e duzentos Reais). Os dados apresentados são valores estimados divulgados pelo ministério da Justiça/DEPEN no Seminário "Sistemas Penitenciários e Direitos Fundamentais realizados em 16 e 17 de Abril de 2008".
} 
Artigo original

Hegemonia - Revista Eletrônica de Relações Internacionais do Centro Universitário Unieuro

ISSN: $1809-1261$

UNIEURO, Brasília, número Especial, 2016, pp. 28-45.

Direito à Educação4. O gasto é de $15 \mathrm{mil} x$ aluno no Ensino Superior enquanto os Estados gastam 21 mil $x$ ano $x$ preso. Uma torneira aberta, onde talentos são perdidos, jogados literalmente fora, longe do alcance de expectativas de realização, de sonhos a serem alcançados, de receber sorrisos e aplausos.

Considerando hoje os projetos de atividades educacionais existentes dentro do Sistema Penal, observa-se o processo de inclusão quase nulo proposto pelo atual modelo. Assim como o trabalho no cárcere, as atividades educacionais não atendem a grande maioria dos apenados. Segundo o INFOPEN/DEPEN/MJ 2009, somente 39.653 internos $(9,68 \%)$ estão estudando no cárcere. Destes, 26,31\% estão matriculados em atividades de alfabetização, 55\% no Ensino Fundamental; 15,79\% no Ensino Médio; 0,25\% no Ensino Superior; e 2,63\% em Cursos Técnicos" (Diretrizes Nacionais).

Os recursos do FUNPEN nos últimos 14 anos de existência foram destinados a melhora da infra-instrutura do Sistema Penitenciário, contabilizando $\mathrm{R} \$ 1.300 .348 .475,00$ (93,4\%) dos recursos investidos nos estados de 1995 a 2007. Apenas R\$92.829.192,00 (6,6\%) dos recursos utilizados pelos estados foram investidos em 453 projetos objetivando ampliação das aplicações das penas alternativas no país, bem como a capacitação dos agentes operadores da execução penal, a elevação da escolaridade e a capacitação profissional dos apenados, a implementação de projetos laborativos e de assistência ao interno, ao egresso e seus familiares, demonstrando claramente a falta de interesse em oferecer oportunidade de acesso a bens que possam

\footnotetext{
${ }^{4}$ Entrevista concedida à Rev. Agora (versão online). Visitada em 14.05.2015.
} 
Artigo original

Hegemonia - Revista Eletrônica de Relações Internacionais do Centro Universitário Unieuro

ISSN: $1809-1261$

UNIEURO, Brasília, número Especial, 2016, pp. 28-45.

melhorar a condição do ser humano enquanto ser pensante capaz de superar sua condição.

As consequências desse círculo vicioso são reincidência, um movimento perverso de entrada e saída contínua das delegacias e presídios e consequentemente, um aumento estatisticamente comprovado da criminalidade e violência. "[...] os motivos de reincidência: sistema carcerário, deficiência de programas de reabilitação, condições prisionais difíceis e exposição a redes criminosas nos cárceres" (BRICEÑO-León, et al, 2013).

Segundo Luiz Flávio Gomes, do Instituto Avante Brasil "o equívoco da política encarceradora massiva irracional (típica dos países capitalistas selvagens e extrativistas) que só conta com a legislação simbólica (ilusória), está sempre acompanhada do abandono da educação e da prática da assistência social a quem necessita desse tipo de atenção" 5 .

A atual situação dos apenados fere profundamente a Constituição que apregoa em seu art. $5^{0}$ inciso XLIX "é assegurado aos presos o respeito à integridade física e moral", ao garantir a educação como direito constitucional, afiançou em seu Art. 208, aos jovens e adultos o Direito Público Subjetivo ao Ensino Fundamental Público e Gratuito. Para que este direito seja efetivado é preciso mais que a Lei. É preciso vontade política, planejamento e recursos humanos e financeiros, os seja, colocar em prática aquilo que as Diretrizes Nacionais: oferta de

${ }^{5}$ Www.institutoavantebrasil.com.br, visitado em 14.05.2015. 
Artigo original

Hegemonia - Revista Eletrônica de Relações Internacionais do Centro Universitário Unieuro

ISSN: $1809-1261$

UNIEURO, Brasília, número Especial, 2016, pp. 28-45.

educação para jovens e adultos em privação de liberdade, definiu como conduta necessária a este segmento da população.

Constata-se que o perfil das vítimas de homicídio foi semelhante ao perfil dos encarcerados. Para cada grupo de 100 mil jovens acima de 18 anos havia 648 jovens encarcerados, enquanto para cada grupo de 100 mil habitantes não jovens 251 encarcerados, ou seja, proporcionalmente o encarceramento de jovens foi 2,5 vezes maior que os não jovens. O que infere a afirmação que tanto a população prisional como as vítimas de homicídio no Brasil são, predominantemente jovens.

\section{Considerações finais}

Considerando o crescente envelhecimento da população e a perda de grande parcela de jovens em idade produtiva que fica fora do mercado de trabalho é no mínimo ingênuo, senão perverso para o Plano de Desenvolvimento Nacional deixar esta população vivendo a expensas do estado, - improdutiva - submetida à formação para o crime. Pergunta-se a quem interessa o aumento ou até a ampliação da população carcerária. O medo como forma de sustentação de uma sociedade, em sua rotina diária, não produz desenvolvimento, mas mais violência.

Que educação oferecer ao jovem preso? Começa com a discussão do conceito de Direito passando pelo acesso e chegando à qualidade vários são os entraves a serem superados - na disputa entre segurança e educação a primeira sempre vence pois tem o poder da guarda. Os jovens em privação de liberdade ficam na fila esperando vagas que não 
Artigo original

Hegemonia - Revista Eletrônica de Relações Internacionais do Centro Universitário Unieuro

ISSN: $1809-1261$

UNIEURO, Brasília, número Especial, 2016, pp. 28-45.

existem. Para eles, a Escola representa a possibilidade de ressocialização através da oportunidade educacional. É necessário um novo olhar para este aluno, além de adequar a instituição escolar, os métodos, os conteúdos, os currículos, etc. é fundamental a compreensão da necessidade de acolhida, entendendo que é cidadão de Direito e sua reivindicação é legítima e amparada pela Constituição.

Não é possível insistir em reputar ao indivíduo a responsabilidade por seu sucesso ou fracasso. A desigualdade social existente na sociedade brasileira não se explica, exclusivamente, por uma distribuição desigual do conhecimento, mas sim pelas próprias características deste modelo econômico que tende a concentrar, de forma contínua, a riqueza historicamente produzida. O acesso à produção cultural é reflexo das desigualdades geradas por este modelo de produção. Consequentemente, não poderia a educação corrigir aquilo que se edifica na própria estrutura econômica existente.

O desenvolvimento de uma nação se dá por um conjunto de fatores e a educação escolar é um deles. Porém, não suficiente. Além do investimento na formação e qualificação da força de trabalho, o que daria maior acesso da população à riqueza produzida, faz-se necessário uma mudança das relações de poder e uma radical mudança no sistema de produção. O que temos hoje no Brasil através dos programas sociais é um alívio da pobreza. Sua erradicação e a possibilidade de mudança de status da população passa também pela escola mas, principalmente, por uma escola de qualidade. Que realmente invista na preparação efetiva dos alunos, proporcionando ferramentas eficazes de disputa pelo "lugar ao sol" para a maioria que 
Artigo original

Hegemonia - Revista Eletrônica de Relações Internacionais do Centro Universitário Unieuro

ISSN: $1809-1261$

UNIEURO, Brasília, número Especial, 2016, pp. 28-45.

tem na educação sua única chance concreta de superação e de mobilidade social.

E, em se tratando da população carcerária, uma oportunidade de resgatar a condição humana, elementar para que possa voltar a sonhar e vislumbrar uma saída para a precária condição a que está submetida. Da mesma forma que o trabalho, é a educação um dos recursos de ressocialização, de elevação da auto-estima e de aposta no futuro.

\section{Referências}

BRICEÑO-León, et alli . Violencia urbana y salud pública en Latinoamérica: un marco sociológico explicativo. Cadernos de Saúde Pública, v. 21, n. 6, p. 1.629-1.648, nov./dez. 2005a

BRASIL. Constituição da República Federativa do Brasil: promulgada em 5 de outubro de 1988, 21 a Ed. São Paulo: Saraiva, 1999.

.Diretrizes Nacionais para oferta de educação para jovens e adultos em situação de privação de liberdade nos estabelecimentos penais. Brasília, D.O.U. 07.05.2010.

. IBGE. Diretoria de Pesquisas. Departamento de população e indicadores sociais. Pesquisa de Informações Básicas 1999. Rio de Janeiro: IBGE, 1999.

.Lei de Diretrizes e Bases da Educação Nacional. Ministério da Educação, Brasília. portal.mec.gov.br/arquivos/pdf/ldb.pdf 
Artigo original

Hegemonia - Revista Eletrônica de Relações Internacionais do Centro Universitário Unieuro

ISSN: $1809-1261$

UNIEURO, Brasília, número Especial, 2016, pp. 28-45.

Mapa do encarceramento: os jovens do Brasil. Secretaria Geral da Presidência da República. Brasília, 2014.

.Plano Nacional de Educação, Lei n. 13.005, de 25 de junho de 2014. Presidência da República, Brasília.

NEVES, C.E.B. Ensino Superior no Brasil: expansão, diversificação e inclusão. ANAIS Congresso da Associação de Estudos Latino Americanos (LASA), 2012.

PROGRAMA DAS NAÇÕES UNIDAS PARA O DESENVOLVIMENTO PNUD. Informe regional sobre Desarrollo Humano para América latina y El Caribe. Actuar sobre El futuro, romper La transmissión intergeneracional de La desigualdad. 2010. Disponível em: http//:www.idhalc-actuarsobreelfuturo.org/site/índex.php.

SACAVINO, Direitos humano à educação no Brasil: uma conquista para todos/todas? In: SILVEIRA, R. M. ET AL. (org.) Educação em Direitos Humanos: fundamentos teórico-metodológicos, João Pessoa: Editora Universitária.

WAISELFISZ, J. J. Mapa da Violência III: os jovens do Brasil. Brasília: UNESCO/Instituto Airton Senna/ Ministério da Justiça/SEDH, 2002. sites:

http://IFOPEN/DEPEN/MJ, 2009.

http://institutoavantebrasil.com.br acesso 14.05.2015 - GOMES, Luiz Flávio

http://portal.inep.gov.br/superior-censosuperior-sinopse http://observatóriodoPNE.org.br http://planalto.gov.br/ccivil_03/ato2011-2014/L13005.htm http://educacional.com.br/legislacao/leg_lv.asp http: revistaagora.com.br 2015 
Artigo original

Hegemonia - Revista Eletrônica de Relações Internacionais do Centro Universitário Unieuro

ISSN: $1809-1261$

UNIEURO, Brasília, número Especial, 2016, pp. 28-45.

http://www.mec.gov.br

http://www.inep.gov.br

http://www.fnde.gov.br

http//:www.idhalc-actuarsobreelfuturo.org/site/índex.php. 